\title{
PENGEMBANGAN KARTU REMI KIMIA MENGGUNAKAN MODEL PEMBELAJARAN TGT (TEAMS GAMES TOURNAMENT)TERHADAP HASIL BELAJAR SISWA PADA MATERI POKOK SISTEM KOLOID KELAS XI SMA KORPRI BANJARMASIN
}

\section{Chemistry Playing Cards Development Using TGT (Teams Games Tournament) Learning Model Toward Students' Learning Outcomes on Colloidal System Topic at Class XI SMA KORPRI Banjarmasin}

\author{
Ni Kadek Ayu Sukarsih, Raden Roro Ariessanty Alicia Kusuma Wardhani \\ ,Mohan Taufiq Mashuri \\ Program Studi Pendidikan KimiaFakultas Keguruan dan Ilmu Pendidikan \\ Universitas Islam Kalimantan (Uniska)Muhammad Arsyad Al Banjari, Banjarmasin \\ *email: kadekayusukarsih@gmail.com
}

\begin{abstract}
Abstrak.Penelitian yang dilaksanakan merupakan penelitian R\&D (Research \& Development) dengan menggunakan desain Borg dan Gall. Penelitian ini dilakukan di kelas XI SMA KORPRI Banjarmasin denganjumlah siswa 32 orang.Teknik pengumpulan data menggunakan pre-test dan post-test. Uji kelayakan produk di lakukan dengan menggunakan skala likert. Uji validitas instrumen hasil belajar dilakukan dengan menggunakan rumus product moment, uji reabilitas instrumen hasil belajar dilakukan dengan menggunakan rumus Alpha, dan hasil belajar siswa diukur menggunakan persentasi skor. Dari hasil penelitian produk pengembangan kartu remi kimia menggunakan model pembelajaran TGT (Teams Games Tournament) mampu meningkatkan hasil belajar siswa. Berdasarkan uji kelayakan produk yang dilakukan didapatkan nilai untuk setiap aspeknya yaitu aspek kebahasaan dan kegrafisan mendapat kriteria sangatbaik. Sedangkan untuk kelayakan isi, TGT dan kegrafisan mendapat kriteria B yaitu Baik. Untuk uji validitas instrumen hasil belajar dengan taraf signifikan 5\% r tabel 0,444 didapatkan 13 butir instrumen hasil belajar valid dari 30 butir instrumen hasil belajar. Untuk uji reabilitas instrumen hasil belajar mendapatkan nilai 1,032 dan hasil belajar mengalami peningkatan dengan $57,01 \%$.
\end{abstract}

Kata Kunci: KartuRemi Kimia, Model pembelajaran TGT (Teams Games Tournament), HasilBelajar, SistemKoloid.

\begin{abstract}
Research conducted is $R \& D$ (Research \& Development) research by using Borg and Galldesign. This research was conducted in class XI SMA KORPRI Banjarmasin with 32 students in total. Data collection techniques were pre-test and post-test. Product feasibility test was done by using Likert scale. Validity test of the learning outcomes instrument was done by using product moment formulation, learning outcomes instrument reliability test was done by using Alpha formulation, and students' learning outcomes were measured by using score percentage. From the research result, chemistry playing cardsdevelopment using TGT (Teams Games Tournament) learning model can improve students' learning outcomes. Based on the product feasibility test, the value for every aspect which are linguistic and graphic aspects werein A criteria as very good. As for the feasibility of content, TGT and graphic got B criteria that is Good. For validity test of learning outcomes instrument with significant level of 5\% r table of 0.444 obtained 13 items were valid out oftotal 30 items of learning outcomes instrument. For instrument
\end{abstract}


reliability test gainned value of 1,032 and learning outcomes increased by $57.01 \%$

\section{Keywords: Chemistry Playing Card, TGT Learning Model (Teams Games} Tournament), Learning Outcomes, Colloidal System.

\section{PENDAHULUAN}

Pendidikan merupakan suatu proses perubahan sikap dan perilaku seseorang dalam upaya mendewasakan manusia melalui proses pembelajaran. Proses pendidikan juga mengarah pada pembentukan sikap, pengembangan intelektual, dan pengembangan keterampilan peserta didik sehingga arah dan tujuan pendidikan dapat tercapai (Siswati, Sunarno, \& Suparmini, 2012).

Berdasarkan hasil observasi selama Program Pengenalan Lapangan II (PPL II) pada bulan Agustus sampai dengan November dan wawancara dengan guru kimia SMA KORPRI Banjarmasin, banyak siswa menganggap pelajaran kimia tidak menarik, membosankan dan sulit untuk dipahami, hal ini dibuktikan dengan hasil ulangan dan ketuntasan belajar yang dicapai antara 50-70. Berdasarkan kurikulum KTSP,setiap siswa harus mencapai nilai yang ditetapkan sekolah sebagai nilai KKM (Kriteria Ketuntasan Mengajar). Proses KBM (Kegiatan Belajar Mengajar) diatas masih disampaikan sebatas sebagai produk. Siswa hanya mendengarkan dan mencatat hal-hal yang dianggap penting serta dituntut untuk menghafal rumusrumus, teori dan hukum. Hal ini menyebabkan siswa mudah merasa jenuh dengan pembelajaran yang menyebabkan proses pembelajaran tidak sesuai yang diinginkan. Salah satu faktor yang menimbulkan anggapan tersebut yaitu model dan media pembelajaran yang kurang menarik membuat siswa kurang aktif saat proses belajar mengajar berlangsung sehingga tidak memperoleh hasil belajar sesuai tujuan yang diharapkan.

Memilih media disertai model pembelajaran merupakan salah satu hal yang sangat penting dalam proses belajar mengajar agar tercapainya hasil belajar yang optimal. Banyaknya media yang bermunculan dan variatif serta sederhana hadir dalam kemasan yang tidak jauh berbeda dengan media yang canggih. Media sederhana yang sangat mudah digunakan dan tidak membutuhkan teknologi dengan fasilitas yang terbatas salah satunya adalah media kartu remi kimia. Media kartu remi kimia pada dasarnya merupakan media gambar yang berbentuk kartu, dengan menggunakan tata cara permainan kartu remi. Media kartu remi pada dasarnya merupakan media gambar yang berbentuk kartu.

Salah satu bagian materi yang dipelajari peserta didik disekolah adalah mengenai koloid, yang dalam praktik biasanya guru menggunakan metode ceramah. Pada metode pembelajaran ini, kedudukan dan peran guru cenderung lebih dominan, sedangkan keaktifan peserta didik terlalu rendah. Oleh karena itu, diperlukan suatu variasi pengajar agar keaktifan peserta didik dapat berimbang dan kemampuan kreatifitasnya juga dapat direalisasikan secara nyata. Menurut Mursiti(2009)anak didik akan lebih mudah menerima materi pembelajaran jika menggunakan alat bantu yang dapat diintregasikan pada seluruh kegiatan belajar mengajar.

Salah satu usaha yang dilakukan adalah dengan menerapkan media pembelajaran kartu remi menggunakan model pembelajaran TGT (Teams Games Tournament) yang mempunyai karakteristik menggabungkan contoh-contoh dari bentuk koloid sehingga menjadi sesuai. Metode permainan dapat membantu siswa merasa nyaman pada saat belajar dan merasa senang kemudian menjadi lebih mudah untuk mengajak mereka belajar. Belajar tidak mungkin dipaksakan. Seperti yang diungkapkan oleh Komariyah \& Soeparno (2010)pelajaran dengan nuansa bermain 
diterima secara menyenangkan, memiliki sifat dasar menghibur dan menggembirakan. Media pembelajaran bukan berfungsi untuk menggantikan guru mengajar di kelas karena guru tidak akan tergantikan posisinya. Media pembelajaran berfungsi untuk membantu guru dan guru di kelas berfungsi sebagai fasilitator untuk membantu siswa yang kesulitan belajar di kelas. Upaya tersebut diharapkan dapat menunjukkan pada siswa bahwa pelajaran kimia itu menyenangkan, tidak menakutkan dan tidak sulit sehingga diharapkan bisa meningkatkan hasil belajar siswa. Media pembelajaran hendaknya lebih disesuaikan dengan keefektivitasan, manfaat dan penggunaannya dalam proses pembelajaran dapat tercapai dan meningkatkan hasil belajar siswa. Permainan dikemas dalam bentuk turnamen dimana siswa memainkan permainan dengan anggota-anggota tim lain untuk memperoleh skor bagi tim mereka masing-masing, permainan ini dapat berperan sebagai penilaian alternatif atau dapat pula sebagai review materi pembelajaran.

Hasil penelitian Ulfa (2013)menunjukkan bahwa pengembangan media kartu pada pembelajaran pokok bahasan struktur atom dan sistem periodik unsur dapat digunakan sebagai acuan bagi guru secara keseluruhan berdasarkan penilaian reviewer (tiga orang guru Kimia SMA/MA) adalah sangat baik (SB) dengan skor 69,3 dan persentase keidealan sebesar 92,4\%. Sedangkan menurut sepuluh peserta didik SMA/MA kelas X memperoleh skor respon 19,1 dan persentase keidealan sebesar 95,5\%. Hasil penelitian Rigasariet al. (2015) dalam jurnal pendidikan fisika menunjukan model pembelajaran TGT (Teams Games Tournament) disertai media kartu remi fisika bahwa ada perbedaan yang signifikan antara hasil belajar siswa pada kelas yang menerapkan ini dibandingkan dengan menggunakan pembelajaran langsung.

Media kartu kimia ini memberikan kesempatan kepada siswa untuk belajar secara aktif dan menumbuhkan kemampuan kreatif dalam memahami materi kimia menggunakan permainan. Bentuk permainan kartu remi dalam pembelajaran kimia tidak jauh berbeda dengan permainan kartu remi yang ditemui pada kehidupan sehari-hari. Perbedaan utamanya terletak pada kartu-kartunya dan aturan permainannya serta didalamnya tulisan dan gambar yang berupa pertanyaan. Kegunaannya adalah untuk melatih keterampilan dan daya ingat siswa serta meningkatkan minat siswa dalam belajar.

\section{METODE PENELITIAN}

Jenis penelitian yang digunakan pada penelitian ini adalah Penelitian dan Pengembangan atau R\&D(Research and Development). Penelitian dan pengembangan bidang pendidikan adalah suatu proses yang digunakan untuk mengembangkan dan mengesahkan produk bidang pendidikan. Langkah-langkah dalam proses ini pada umumnya di kenal sebagai siklus $R \& D$, yang terdiri dari pengkajian terhadap hasil-hasil penelitian sebelumnya yang berkaitan dengan validitas komponen-komponen pada produk yang akan dikembangkan, pengembangan menjadi sebuah produk, pengujian terhadap produk yang dirancang, dan peninjauan ulang dan mengoreksi produk tersebut berdasarkan uji coba.

Hasil dari eksplorasi permasalahan yang dilakukan dalam analisis kemudian dijadikan landasan untuk menyusun produk desain media pembelajaran kartu remi kimia. Pada penelitian ini, pelaksanaan penelitian metode R\&D mengikuti pada prosedur yang dikembangkan oleh Borg dan Gall dari tahap 1 sampai dengan langkah 10. Berikut pengembangkan 10 tahapan dalam mengembangkan model, yaitu :

1. Melakukan penelitian pendahuluan dan pengumpulan data awal (Research and Information Collecting) termasuk : 
a. Analisis kebutuhan: untuk melakukan analisis kebutuhan ada beberapa kritetia, yaitu: 1) Apakah produk yang akan dikembangkan merupakan hal yang penting bagi pendidikan? 2) Apakah produknya mempunyai kemungkinan untuk dikembangkan? 3)Apakah SDM yang memiliki keterampilan, pengetahuan dan pengalaman yang akan mengembangkan produk tersebut ada? 4) Apakah wa ktu untuk mengembangkan produk tersebut cukup?

b. Studi literatur: Studi literatur dilakukan untuk pengenalan sementara terhadap produk yang akan dikembangkan. Studi literatur ini dikerjakan untuk mengumpulkan temuan riset dan informasi lain yang bersangkutan dengan pengembangan produk yang akan direncanakan.

c. Riset skala kecil: Pengembangan sering mempunyai pertanyaan yang tidak bisa dijawab dengan mengacu pada riset belajar atau teks profesional. Oleh karenanya pengembang perlu melakukan riset skala kecil untuk mengetahui beberapa hal tentang produk yang akan dikembangkan.

2. Merencanakan penelitian (planning), hal penting dalam perencanaan adalah pernyataan tujuan yang harus dicapai produk yang akan dikembangkan.

3. Mengembangkan desain produk awal (develop preliminary of product) meliputi: penyiapan materi pembelajaran, penyusunan buku pegangan, dan perangkat evaluasi.

4. Melakukan uji tahap awal (preliminary field testing), yaitu evaluasi pakar bidang desain pembelajaran, teknologi informasi, dan multimedia.

5. Melakukan revisi terhadap produk utama (main product revision), berdasarkan masukan dan saran-saran dari hasil uji lapangan awal.

6. Melakukan uji coba lapangan (main field test), digunakan untuk mendapatkan evaluasi atas produk. Evalusi dibuat untuk mengetahui hasil belajar siswa yang menjadi Objek Uji Coba penelitian.

7. Melakuakan revisi terhadap produk operasional (operational product revision), berdasarkan masukan dan saran-saran hasil uji lapangan dan praktisi pendidikan.

8. Melakukan uji lapangan operasional (operational field testing).

9. Melakukan perbaikan terhadap produk akhir (final product revision), berdasarkan pada uji lapangan.

10. Melakukan desiminasi dan implementasi produk (dissemination and implementation), serta menyebarluaskan produk.

Untuk keperluan penelitian yang merupakan penelitian skala kecil maka penelitian dihentikan pada langkah ke enam karena pada langkah ke enam dilakukan pengukuran hasil belajar siswa sedangkan pada langkah ke tujuh, delapan, sembilan dan sepuluh membutuhkan biaya yang mahal dan cakupan yang sangat luas dan waktu yang lama.

Uji coba produk juga dilakukan terhadap media yang digunakan. Uji coba merupakan tolak ukur keberhasilan dalam mengembangkan sebuah produk bahan ajar. Uji coba dilakukan bertujuan untuk mendapatkan saran maupun tanggapan melalui penilaian terhadap kartu remi kimia tersebut, kemudian dilakukan revisi untuk mencapai kelayakan produk yang akan dikembangkan. Dalam pelaksanaan uji coba tersebut akan dilakukan enam tahap yaitu tahap satu sampai tahap enam.

\section{HASIL DAN PEMBAHASAN}

Media pembelajaran kartu remi kimia menggunakan model pembelajaran TGT (Teams Games Tournament) ini dibuat sebayak 52 macam kartu diantaranya : 
Tabel 1. Keterangan jenis dan jumlah kartu remi kimia

\begin{tabular}{lll}
\hline No & Keterangan yang termuat dalam kartu & jumlah \\
\hline 1 & Kartu J & 4 \\
2 & Kartu Q & 4 \\
3 & Kartu K & 4 \\
4 & Kartu nomor 1 sampai 4 & 40 \\
\hline
\end{tabular}

Produk media pembelajaran kartu remi kimia menggunakan model pembelajaran TGT diuji kelayakannya oleh para ahli masing-masing aspek. Adapun hasil dari uji kelayakan media pembelajaran kartu remi kimia menggunakan model pembelajaran TGT sebagai berikut :

\section{Tabel 2. Hasil uji kelayakan kartu remi kimia}

\begin{tabular}{llll}
\hline No & Aspek & Hasil & Kriteria \\
\hline 1 & Kebahasaan & Sangat baik & A \\
2 & Kegrafisan & Baik & B \\
3 & TGT (Teams Games Tournamen) & Baik & B \\
4 & Kelayakan isi & Baik & B \\
5 & Penyajian & Sangat baik & A \\
\hline
\end{tabular}

Berdasarkan analisis validitas tes hasil belajar kimia dari 30 butir soal yang diujicobakan diperoleh hasil yaitu 13 butir soal yang valid dan 17 butir soal yang tidak valid. Instrumen hasil belajar yang digunakan adalah item dengan status butir soal valid dan untuk butir soal dengan status tidak valid tidak digunakan.

Analisis perhitungan reliabilitas instrumen hasil belajar kimia siswa berdasarkan perhitungan diperoleh reabilitas keseluruhan butir tes sebesar 1,032, sehingga dapat disimpulkan bahwa butir-butir instrumen hasil belajar kimia siswa memiliki reabilitas tinggi

Berdasarkan data nilai pre-test diketahui nilai rata-rata siswa, yaitu 28,88 . Adapun berdasarkan data nilai post-test yang diperoleh, nilai rata-rata siswa adalah 85,89. Perbedaan nilai rata-rata post-testdanpre-testyang dapat dilihat dari rata-rata nilai post-test diatas KKM yaitu 70 ini merupakan dampak dari penggunakan kartu remi kimia menggunakan model pembelajaran TGT (Teams Games Tournament).

\section{SIMPULAN}

Berdasarkan uraian hasil penelitian dapat disimpulkan bahwa media pembelajaran kartu remi kimia menggunakan model pembelajaran TGT (Teams Games Tournament) efektif terhadap peningkatan hasil belajar siswa untuk materi pokok sistem koloid hal ini ditunjukan dengan adanya peningkatan 57,01\% dan kelayakan media tergolong dalam kriteria Baik dan layak digunakan dalam penelitian.

Berdasarkan hasil penelitian dan kesimpulan dalam penelitian ini, peneliti menyampaikan beberapa saran antara lain guru dapat memanfaatkan media pembelajaran kartu remi kimia menggunakan model pembelajaran TGT (Teams Games Tournament) ini sebagai sarana untuk membantu dalam meningkatkan hasil belajar siswa pada materi pokok sistem koloid. Untuk itu, diperlukan sarana kertas yang cocok dan baik untuk digunakan membuat media pembelajaran kartu remi kimia menggunakan model pembelajaran TGT ini.Selain itu, perlu diadakan penelitian lebih lanjut untuk menguji keefektifan penggunaan media pembelajaran kartu remi kimia menggunakan model pembelajaran TGT terhadap hasil belajar siswa pada materi pokok sistem koloid. Pengujian lebih lanjut ini memerlukan 
waktu dan dana yang cukup banyak tetapi akan menghasilkan sarana dan perbaikan yang tepat.

\section{DAFTAR RUJUKAN}

Asyhar, R. (2012). Kreatif Mengembangkan Media Pembelajaran. Jakarta: Referensi Jakarta.

Budi, Utami, et al. (2009). Kimia 2: Untuk SMA/MA. Jakarta: Departemen Pendidikan Nasional.

Hamalik, \& Oemar. (2010). Proses Belajar Mengajar. Jakarta: PT Bumi Aksara.

Hamdani. (2011). Strategi Belajar Mengajar. Bandung: Pustaka Setia.

Hart, A., \& Suss, D. (2002). Media Education in 12 European Countries, A Comparative Study of Teaching Media in Secondary School. Zurich: Ecollection of The Swiss Federal Institute of Technology.

Indriana, D. (2011). Ragam Alat Bantu Media Pembelajaran: Mengenal, Merancang, dan Mempraktikannya. Jogjakarta: Diva Press.

Komariyah, Z., \& Soeparno. (2010). Pengaruh Pemanfaatan Media Permainan Kartu Hitung Terhadap Hasil Belajar Siswa Materi Ajar Operasi Hitung Campuran Mata Pelajaran Matematika Kelas III SDN Babat Jerawat I Surabaya. Kurikukulum dan Teknologi Pendidikan, 10(1), 66.

Kustandi, C., \& Sutjipto, B. (2011). Media Pembelajaran Manual dan Digital. Bogor: Ghalia Indonesia.

Munadi, Y. (2008). Media Pembelajaran Sebuah Pendekatan Baru. Jakarta: Cipta Gaung Persada Press.

Mursiti, S., \& dkk. (2009). Pengaruh Penggunaan Ular Tangga Redoks Sebagai Media Chemo-Edutainment Bervisi Sets Terhadap Hasil Belajar Siswa SMA. Jurnal Inovasi Pendidikan Kimia, 3(1), 458-462.

Naim, N. (2011). Dasar-dasar Komunikasi Pendidikan. In P. Fathurrohman, \& S. Sutikno, Strategi Belajar Mengajar Melalui Penanaman Konsep Umum dan Konsep Islami (p. 112). Bandung: PT Refika Aditama.

Rigasari, A., Prihandono, T., \& Handayani, R. D. (2015, September). Model Pembelajaran TGT (Teams Games Tournament) Disertai Media Kartu Remi Fisika Dalam Pembelajaran Fisika di SMA. Jurnal Pendidikan Fisika, 4(2), 159-163.

Rusman. (2012). Model-model Pembelajaran. Depok: PT Rajagrafindo Persada.

Sanjaya, W. (2011). Perencanaan dan Desain Sistem Pembelajaran. Jakarta: Kencana.

Siswati, H., Sunarno, W., \& Suparmini. (2012). Pembelajaran Fisika Berbasis Masalah Dengan Menggunakan Metode Demonstrasi Diskusi dan Eksperimen Ditinjau dari Kemampuan Verbal dan Gaya Belajar. Jurnal Inkuri, 1(2), 132-141.

Slameto. (2010). Belajar dan Faktor yang Mempengaruhinya. Jakarta: Rineka Cipta.

Slavin, R. E. (2008). Psikologi Pendidikan: Teori dan Praktik (8 ed.). Jakarta: PT Indeks.

Smaldino, S. E., Lowther, D. L., \& Russel, J. D. (-). Teknologi Pembelajaran dan Media untuk Belajar (2 ed.). Jakarta: Kencana.

Sofyan, A., Feronika, T., \& Malama, B. (2006). Evaluasi Pembelajaran IPA Berbasis Kompetensi (1 ed., Vol. 1). Jakarta: UIN Press.

Sugiyono. (2011). Metode Penelitian Pendidikan. Bandung: Alfabeta.

Sugiyono. (2015). Metode Penelitian Pendidikan (Pendekatan Kuantitatif dan R\&D) (15 ed.). Bandung: Alfabeta. 
Dalton : Jurnal Pendidikan Kimia dan Ilmu Kimia, Volume 1 Nomor 1, Mei 2018

Syah, M. (2010). Psikolog Pendidikan (II ed.). Bandung: PT Remaja Rosdakarya. Ulfa, A. N. (2013). Pengembangan Media Kartu Bergambar Materi Pokok Struktur Atom dan Sistem Periodik Unsur SMA/MA Kelas X Semester 1 Berdasarkan Standar Isi. Yogyakarta: Universitas Islam Negeri Sunan Kalijaga.

Wibowo, T. (2005, Juli). Pendayagunaan Media Pembelajaran. Jurnal Pendidikan Penabur, IV(4), - .

Wina, S. (2012). Kurikulum dan Pembelajaran Teori dan Praktik Pengembangan Kurikulum Tingkat Satuan Pendidikan (KTSP). Jakarta: Kencana. 